\title{
The altered DNA methylation pattern and its implications in liver cancer
}

\author{
Jing De $\mathrm{ZHU}^{1,2, *}$ \\ ${ }^{1}$ The State-key Laboratory for Oncogenes and Related Genes, Shanghai Cancer Institute, Shanghai Jiaotong University, LN \\ 2200/25, Xietu Road, Shanghai 200032, China. \\ ${ }^{2}$ The Collage of Life Sciences, Zhejiang Science and Technology University, Xiasha University District, Hangzhou, Zhejiang \\ 310018, China.
}

\begin{abstract}
DNA methylation is the most intensively studied epigenetic phenomenon, disturbances of which result in changes in gene transcription, thus exerting drastic imparts onto biological behaviors of cancer. Both the global demethylation and the local hypermethylation have been widely reported in all types of tumors, providing both challenges and opportunities for a better understanding and eventually controlling of the malignance. However, we are still in the very early stage of information accumulation concerning the tumor associated changes in DNA methylation pattern. A number of excellent recent reviews have covered this issue in depth. Therefore, this review will summarize our recent data on DNA methylation profiling in cancers. Perspectives for the future direction in this dynamic and exciting field will also be given.
\end{abstract}

Keywords: DNA methylation, epigenetics, liver cancer, tumor staging and classification.

\section{DNA METHYLATION AND CANCER}

Addition of a methyl group onto the 5 carbon in cytosine of the $\mathrm{CpG}$ dinucleotides is the only found significant covalent modification in DNA from mammalian cells. This has been postulated as an important homeostatic mechanism since about four decades ago when the mosaic type of organization of the eukaryotic genomes was realized., that the CG-rich segments are separated by the AT rich counterparts (for recent reviews see [1,2]). The recent surge of the interests in epigenetics as a whole and in DNA methylation in particular, can be attributed to the urgent need for function dissection and annotation of DNA sequences after the completion of human and various model organism genome projects. It has been amply demonstrated that the tissue-specific gene expression pattern during development is exclusively controlled by the inherited mechanisms without any involvement of DNA sequence change (Epigenetics) in somatic cells, except for those from immune system. The necessity to main-

\footnotetext{
*Correspondence: Jing De ZHU

Tel: +86-21-64224285

E-mail: zhujingde@yahoo.com or zhujingde@sh163.net
}

tain DNA methylation profile in both a time/space specific and ordered manner has been confirmed from genetic studies with the knock-out mice for each of three DNA methyltransferase genes (DNMT1, DNMT3a and DNMT3b), respectively $[3,4]$.

Although genetic defects in genes that are required for establishment and maintenance of the DNA methylation profiles have not been directly linked to cancer formation, it is been generally accepted that cancers do suffer from the wide-spread aberrations in DNA methylation that have the profound etiological implications. In another word, cancer is also an epigenetic disease. Some genetic defects in cancer cells has been directly attributed to the hypermethylation that lead to the expressional loss of the DNA repair genes such as the $h M L H 1$ and MGMT (O6 methylguanine DNA methyltransferase) genes [5]. The protein encoded by the $M G M T$ gene is responsible for removal of the fortuitously added akyl group on the guanine $(\mathrm{G})$ base of DNA to prevent the G to A mutation. In the recto-colon cancer cells where the hypermethylated promoter $\mathrm{CpG}$ island was found in parallel with the transcription silencing of the $M G M T$ gene, there were prevalent $\mathrm{G}$ to A type mutations found in both the ras proto-oncogene and $p 53$ tumor suppressor gene [6,7]. The biochemical inclination of the methylated $\mathrm{C}$, but not the unmethylated, to $\mathrm{T}$ conversion 
has been suggested as a key mechanism both for the $\mathrm{CpG}$ depletion in the genome of high eukaryotes through evolution and the $\mathrm{C}$ to $\mathrm{T}$ mutations in the tumor suppressor gene $p 53$ in human cancer (http://www-p53.iarc.fr/index. $\mathrm{html}$ ). Furthermore, the genetically manipulated mice with a reduced level of the DNMT1 protein suffer from global demethylation in the genome, the increase in point mutation and in tumor formation [8-10]. The etiologically significant events tend to be gathered at the early phase of carcinogenesis. Indeed, hypermethylation of the promoter $\mathrm{CpG}$ island of the $p 16^{I N K 4 a}$ tumor suppressor gene had been detected in the sputum DNA of lung cancer patients, as early as 35 month before diagnosis [11]. In mutated alleles, there is no hypermethylation occurred on the promoter $\mathrm{CpG}$ island nor transcriptional gene silencing [11], suggesting that defects in DNA methylation is independent of the genetic flaws although a frequent cross-talking between them take place. It has been well established that the epigenetic makeup is much more amenable than the genetic counterparts in cell to the environment influences, including nutrients [12], strengthening the notion that in carcinogenesis the epigenetic disturbance probably prelude the genetic defects.

The major epigenetic reprogramming concerning DNA methylation in high eukaryotes occurs at two stages: the maturation of the germ cells and the early embryonic development $[13,14]$. Then, DNA methylation pattern in somatic cells gradually evolve during cell differentiation and aging process. During mitosis and meiosis, DNA methylation pattern is reliably passed to the next generation by a mechanism similar to the semi-conservative replication of DNA. The aging process of high organisms is characteristic with a decrease in the overall level of DNA methylation and an increased in methylation of the promoter $\mathrm{CpG}$ region $[13,15]$. The stochastic events also take place to confer the individuality of the DNA methylation pattern in somatic cells of the same tissue origin, which may contribute to the wide variation in the embryonic development of the cloned fertilized eggs with somatic nuclei [16]. However, to the malignant state of cells, further drastic changes in DNA methylation have to take place. A dramatic reduction of the overall level of DNA methylation down to $25 \%$ to $33 \%$ of the normal was commonly shown in cancer cells. That causes the increase in the transcription/transposition activity of the normally methylated/ transcriptionally silenced repetitive sequences, which compose of up to $40 \%$ of the genome [17], which in turn bring about the genome stability at both the chromosomal and primary sequence levels, an important hallmark of the cancerous state. The local demethylation of the promoter $\mathrm{CpG}$ island has been linked to activation of the otherwise transcriptionally silenced genes including proto-oncogenes
[17]. The local hypermethylation in the promoter $\mathrm{CpG}$ island has been repeatedly reported as an equally important alternative to the mutation/deletion for the inactivation of the tumor suppressor genes [18]. Not all the changes in methylation pattern contribute to tumorigenesis, but rather readout for the dysfunctional epigenetic homeostatic state in cancer cells. However, all the consistent changes should be valuable for tumor staging and classification in clinic. It is, therefore, desirable to profile all the consistent changes in DNA methylation in any given type of cancer, followed by the demonstration of their pathological implication.

During the last decade, enormous amounts of information at the genetic, biochemical and molecular biological levels have been accumulated on cancer formation. The cure of cancer has however not been benefited as both the survival rate and life quality of cancer patients in the Western world have hardly been improved [19]. There is not much progress in staging and classification for solid tumors either, which rely almost exclusively on the observations from clinical, pathological, biochemical, serological and imaging analyses [20]. This unsatisfactory state has been largely attributed to the inherent complexity of the problem that is linked to the huge heterogeneity at all the aspects in cancer mass, including the adaptability to the changing environment. There are other reasons. The gene coding for P53 protein is the most frequently mutated gene in cancer and is required for cell normality [21]. There are 19,806 somatic mutations, 264 germline mutations and functional data on 423 mutant proteins of the TP53 currently available in the designated database (http:/ /www-p53.iarc.fr/index.html). It is thus expected long before the completion of the human genome project that sampling p53 mutations should be valuable to the cancer clinical practice. The reality is however not so encouraging. Why? The human $p 53$ gene consists of 11 exons and 19179 bp DNA sequence in length (www.ncbi.nlm.nih.gov/entrez/ query.fcgi?CMD=Display\&DB=gene). Even without taking into account the phenotypic important mutations in the upstream and downstream flanking sequences that are crucial to its transcription, it is unrealistic to comprehensively profile all possible single nucleotide change within the approximately $20 \mathrm{~kb}$ gene sequence in cancer cells even with the most powerful platform technologies that is currently available. This forms the so called "multiple targets in a single gene" problem coherent with the genetic biomarkers. To establish the expression profiles at either the mRNA or the protein levels, there are other difficulties. The gene expression is frequently affected by the tumor irrelevant known (the biological rhythm related, etc.) and unknown factors. The cellular heterogeneity in clinical materials presents a formidable challenge too. Therefore, 
an exceptional standard of cell purity is demanded for establishment of the genetic and expression profiles in the clinic cancer samples.

On the contrary, many advantages have been identified with the DNA methylation profiling in cancers approached by the methylation-specific PCR (MSP) method. It is possible to detect one tumor cell among as many as $10^{4}$ of normal cells, providing the tumor cells assume a homologously opposite pattern of methylation from their normal counterparts. Hence, the undesirable presence of the non-tumorous cells in the clinical sample can be greatly tolerated. A correlation between the hypermethylated status of the promoter $\mathrm{CpG}$ island and the transcriptional inert status of the tumor suppressor gene has been demonstrated in the majority of cases, suggesting that the methylation status of the promoter $\mathrm{CpG}$ island, is a valuable for monitoring the expression state of the target gene (the single target of the signal gene). Furthermore, the DNA methylation pattern is rather stable biochemically as well as biologically, and does not change by the nontumorous actors that profoundly fluctuate the levels of mRNA or protein in cells. Hence, using the DNA methylation pattern as the sensitive and reliable indicator for cancer status in the clinical setting is both theoretically sound and practically more feasible (Tab. 1).

To realize its great potential, a comprehensive methylation profile with more targets and large patient cohort for any given type of human tumor is needed. Unfortunately, few, if any, methylation profile is qualified. Our efforts remains at the very early phase of discovery even with the most studied type of tumor, the recto-colon cancer and lung cancer $[22,23]$. The primary hepatocellular carci- noma (HCC) that preferentially affects people in China demands more actions of Chinese biomedical scientists.

\section{OUR UNDERSTANDING OF THE ROLE AND POTENTIAL OF THE DNA METHYLATION MEDIATED ETIOLOGICAL MECHANISMS IN LIVER CANCER}

$\mathrm{HCC}$ is one of the most aggressive malignancies (http:/ /www-depdb.iarc.fr/globocan/GLOBOframe.htm), (http:/ /www-dep.iarc.fr/dataava/infodata.htm) in human. Although it is number five in occurrence, it ranks the fourth in mortality worldwide. It also ranks the first in tumorcaused death in mainland of China [24]. The difficulties in early diagnosis and clinical treatment such as its inherent as well as adaptive resistance to the common chemotherapeutic drugs makes it a devastating health threat to the people in China and in many countries of far east Asia and Africa. Three year ago, we started to analyze DNA methylation profile in liver cancers and three other types of cancers, the non-small cell lung cancer (NSCLC), the malignant glioma and the recto-colon cancer ([25-33] and our unpublished observation by $\mathrm{Yu} \mathrm{J}$ et al). Transcription regulation of a number of genes involved in liver cancer formation has also been studied [33-37].

\section{Identification of the critical CpG methylation for tran- scription silencing of the MAGEA1 gene[37]}

A typical CpG island consists of 500-1000 bp in length with up to several dozens of $\mathrm{CpG}$ dinucleotides. Not all of the $\mathrm{CpG}$ dinucleotides would be critical in methylation mediated control of transcription. The $\mathrm{CpG}$ within the criti-

Tab. 1 The characteristics of the molecular biomarkers.

\begin{tabular}{lllll}
\hline & Genetic & Epigenetic & \multicolumn{2}{c}{ Expression } \\
\hline & Mutation, & DNA & mRNA & Protein \\
& SNP, LOH & methylation & & \\
Stability & High & High & Low & Low \\
PCRable & Yes & Yes & Yes & No \\
Target/gene & Multiple & Single & $/$ & $/$ \\
Nature & Quantitative & Qualitative & quantitative & quantitative \\
Sample purity & Essential & Not & Essential & Essential \\
Fluctuation & No & No & Yes & Yes \\
Tumor type specificity & Low & High & Low & Low \\
\hline
\end{tabular}

Note: /: irrelevant; Target/gene: Multiple: more than one target (Single) need to be analyzed. Fluctuation: whether the amount of the biomarkers changes according to the fluctuation of non-tumorous factors (emotional, physiological or pathological factors). 
cal cis-elements for their cognate transcription factors and is more crucial for gene transcription than other $\mathrm{CpG}$. The MAGEA1 gene was hyperrmethylated in the normal liver tissues, but demethylated [26] and presented as a serum protein in over $75 \%$ of liver cancer patients, thus providing us a good model system for identification of the critical $\mathrm{CpG}$ for gene transcription regulation. Among 19 CpG dinucleotides within the promoter, the only $-30 \mathrm{CpG}$ has been found important for methylation mediated transcription control. Supportive observations are the follows: 1) this $\mathrm{CpG}$ is among five $\mathrm{CpG}$ dinucleotides having been methylated in a cell line where this gene is silenced in transcription; 2) the in vitro methylation by MSss I methyltransferase on this $\mathrm{CpG}$ would down-regulate the promoter activity up to $66 \% ; 3$ ) the methylation on this $\mathrm{CpG}$ diminishes a novel DNA-protein interaction. The discovery of the proteins involved should provide us more insights into the DNA methylation mediated control of $M A G E A 1$ gene transcription.

\section{Identification of the novel tumor associated genes with altered methylation pattern in liver cancer (our un- published observations by He Y et al)}

Most of the tumor associated genes were identified by genetic (mutation, deletion and translocation) or/and biochemical methods [38] until a few years ago when Jones and his colleagues used the "methylation sensitive arbitrary primed PCR" [39] approach to identify several tumor associated genes characteristic with the altered DNA methylation pattern. Using this method, we have identified 22 regions, from more than two thousand target bands, showing altered methylation patterns in a live cancer cell line from the normal liver tissues. Among them, two liver cancer associated candidate genes were identified, which were hypermethylated in over $75 \%$ of both cancer tissues and the established tumor cell lines of liver origin, while unmethylated in the normal liver tissues. Cell lines expressing either of these two genes with tet-off regulatable promoters have been established in our lab. The ongoing efforts are to functional annotating these two tumor associated candidate genes in cell culture as well as tumor animal models.

\section{Methylation profiling in liver cancer and other tumors by MSP}

MSP is targeted to the drastic differences of the methylated verse unmethylated cytosine in response to the deamination under the bisulphate treatment [40]. As a result, the unmethylated $\mathrm{C}$ is converted to $\mathrm{T}$, but the methylated $\mathrm{C}$ remains unchanged. However, the procedures including primer design, bisulphate treatment and the PCR reaction remain empirical. We have methylated over one hundred genes in liver cancer in the last three years and achieved a success rate of over $4 / 5$ of the total attempts. Both false negative or positive PCR reactions account for the failure. Using the PCR for the in vitro methylated targets by MSss I as a positive control, we could conclude that the promoter $\mathrm{CpG}$ island of the $C D H 1, p 16^{I N K 4 a}, P T E N$ and $R A S S F 1 C$ genes was unmethylated in the normal healthy liver tissue (Fig. 1A). Before proceeding for largescale methylation-profiling on clinical samples, PCR products for each new target were sequenced to confirm their identity (the $C D H 1$ and $p 16^{I N K 4 a}$ genes, Fig. 1B).

With this well verified MSP procedure, we have methylation-profiled 92 targets (the list of the targets will be provided under request) in samples from liver cancer patients (the size of the patient cohort is 26 to 30 ) [26, 27, $30,31]$ and our unpublished observations (He Y et al). The targets were selected for its clinical implication to cancer formation, among which over $2 / 3$ were the first time investigated. To eliminate any non-tumorous changes, the liver tissues from four healthy donors were collected as the normal control. Among 92 targets, 32 exhibited changes in methylation pattern at various frequencies: 7 targets (MAGEA1, ASPH, OXCT, MTHFD2, SRP72, $E N O 3$, and $M D F I$ ) had the reduced level of methylation and 25 (RASSF1A, GSPT1, SALL3, OCT6, CFTR, AR, p73, cyclin a1, MYOD1, p16 ${ }^{I N K 4 a}, A B O, D B C C R 1, I T G A 9$, IRF7, LRP6, PENK, WT1, CDH13, DKC1, CSPG2, GALR2, $57^{\text {KIP2 }}, M T 1 A, H I C 1$ and $C A T$ ) had the increased level of methylation (Fig. 2). There is no correlation observed between the methylation changes and the known clinical and pathological parameters such as the tumor staging and classification, age, and HBV infection. Further verification is underway with a large patient cohort.

Tumor is a systems disease. The pathologically defined neighbouring non-cancerous tissues are likely experiencing the early stage changes of the carcinogenesis (Fig. $3 \mathrm{~A})$. We, therefore, defined the targets that show significant difference in frequencies between the tumor(C) and the neighbouring tissues $(\mathrm{N})$ as the late phase and the otherwise as the early phase changed gene in DNA methylation, by taking the normal healthy liver tissue (M) as the reference (Fig. 3B). The following genes fall into the category of the early phase specific, CSPG2, OXCT, cyclin a1, RASSF1A, ABO,WT1, GALR2, p57 ${ }^{K I P 2}, M A G E A 1$, $M T 1 A, C D H 13, M Y O D 1, D K C 1$, and HIC1; while the late phase specific genes are DBCCR1, PENK, IRF7, GSPT1, p73, OCT6, p16 $6^{I N K 4 a}, S A L L 3$, and AR.

The availability of the methylation profile of as many as 32 genes in HCC has made possible to detect concordant behaviour of the targets by a mathematical method "Discovery association rule" [41]. This information should provide a valuable guidance for target selection in assays 
DNA methylation in liver cancer

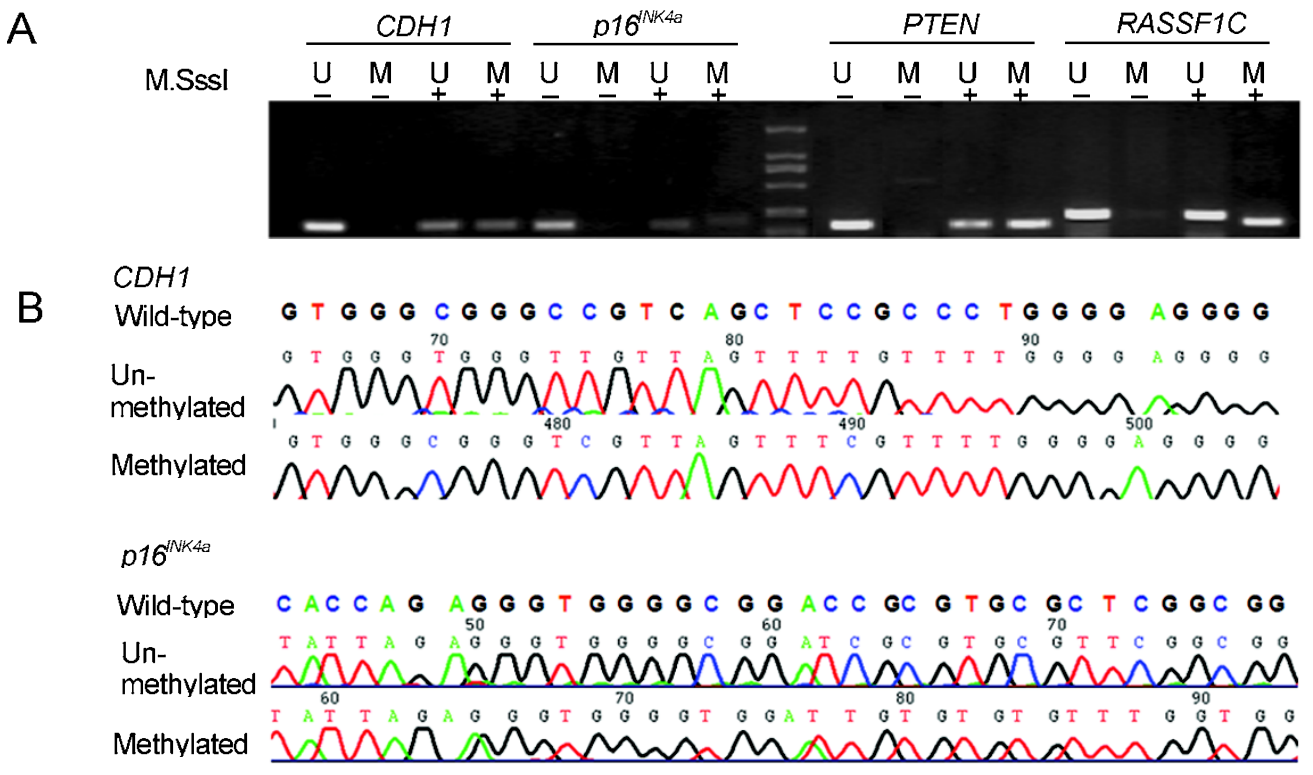

Fig. 1 The piloting experiments for the methylation specific PCR reactions. (A) DNAs from the normal liver tissue were methylated (+) with MSss I methyl transferase in vitro, followed by MSP analysis with each pair of primers specific to the methylated and unmethylated allele. -, the untreated DNA; U, with the primer for the unmethylated, and M, the methylated targets, respectively. (B) the sequence verification of the methylated and unmethylated allele of $C D H 1$ and $p 16^{I N K 4 a}$ genes.

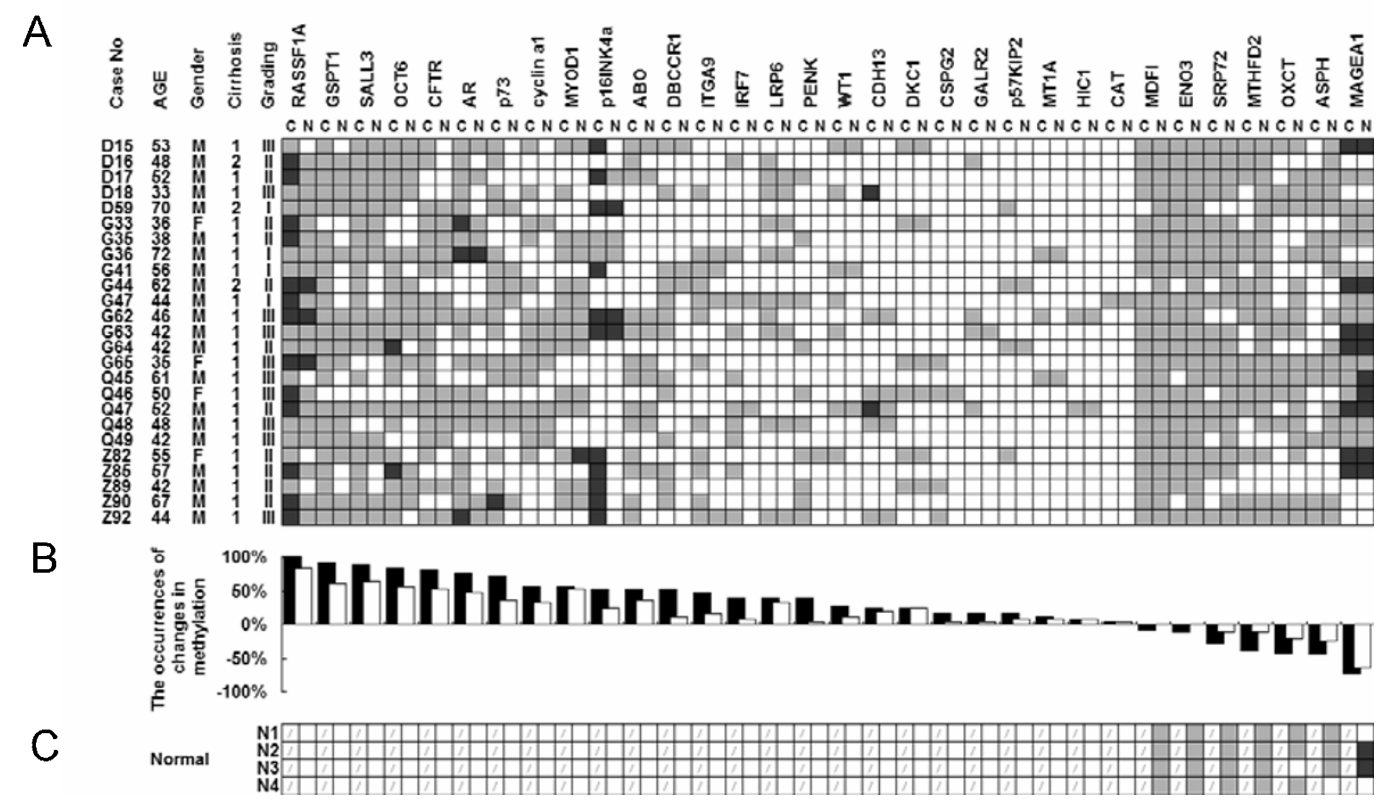

Fig.2 The altered methylation pattern of the promoter $\mathrm{CpG}$ island of the genes in liver cancer. (A) the detail profile of altered methylation pattern in the clinical samples. (B) the graphic presentation of the data in $(\mathbf{A})$. C, cancer tissues and $\mathrm{N}$, the neighboring non-cancerous tissues), in comparison with the pattern in the normal liver tissues $(\mathbf{C})$. The empty box: homologously unmethylated. The filled box: homologously methylated and the grey box: heterologously methylated. 


\begin{tabular}{|c|c|c|c|c|c|c|c|c|c|}
\hline & & & & rly & & & & & \\
\hline Altered & tter & & & & & & & & \\
\hline Nor & nal & & & & & & & & \\
\hline & le ea & y ph & & & & & & & \\
\hline & $\mathrm{C} / \mathrm{M}$ & $\mathrm{N} / \mathrm{M}$ & $x^{2}$ & $p$ & & The & ate $p$ & se & \\
\hline CSPG2 & $5 / 26$ & $1 / 26$ & 3.014 & 0.083 & & $\mathrm{C} / \mathrm{M}$ & $\mathrm{N} / \mathrm{M}$ & $\chi^{2}$ & $\mathrm{p}$ \\
\hline$O X C T$ & $13 / 25$ & $7 / 25$ & 3.000 & 0.083 & DBCCR1 & $14 / 26$ & $3 / 26$ & 10.575 & 0.001 \\
\hline \begin{tabular}{|l} 
cyclin a1 \\
RASSF1A \\
\end{tabular} & $\begin{array}{l}14 / 26 \\
25 / 26\end{array}$ & $\begin{array}{r}8 / 26 \\
22 / 26\end{array}$ & $\begin{array}{l}2.836 \\
1.991\end{array}$ & $\begin{array}{l}0.092 \\
0.158\end{array}$ & PENK & $10 / 26$ & $1 / 26$ & 9.339 & 0.002 \\
\hline $\mathrm{ABO}$ & $14 / 26$ & $9 / 26$ & 1.949 & 0.163 & IRF7 & $11 / 26$ & $2 / 26$ & 8.308 & 0.004 \\
\hline WT1 & $8 / 26$ & $4 / 26$ & 1.733 & 0.188 & GSTP1 & $24 / 26$ & $16 / 26$ & 6.933 & 0.008 \\
\hline \begin{tabular}{|l|} 
GALR2 \\
\end{tabular} & $5 / 26$ & $2 / 26$ & 1.486 & 0.223 & p73 & $19 / 26$ & $10 / 26$ & 6.315 & 0.012 \\
\hline \begin{tabular}{|l} 
p57 $7^{\mathrm{K} P 2} 2$ \\
MAGEA1
\end{tabular} & $\begin{array}{r}4 / 26 \\
19 / 26\end{array}$ & $\begin{array}{r}2 / 26 \\
17 / 26\end{array}$ & \begin{tabular}{|l|}
0.754 \\
0.361
\end{tabular} & $\begin{array}{l}0.385 \\
0.548\end{array}$ & Ост6 & $22 / 26$ & $14 / 26$ & 5.778 & 0.016 \\
\hline MT1A & $3 / 26$ & $2 / 26$ & 0.221 & 0.638 & $\mathrm{p} 16^{\mathrm{INK} / \mathrm{a}}$ & $14 / 26$ & $6 / 26$ & 5.200 & 0.023 \\
\hline MTHFD2 & $15 / 26$ & $14 / 26$ & 0.197 & 0.657 & SALL3 & $23 / 26$ & $17 / 26$ & 3.900 & 0.048 \\
\hline $\mathrm{CDH} 13$ & $6 / 26$ & $5 / 26$ & 0.115 & 0.734 & $A R$ & $19 / 26$ & $12 / 26$ & 3.914 & 0.048 \\
\hline $\begin{array}{l}\text { MYOD1 } \\
\text { DKC1 }\end{array}$ & $15 / 26$ & $\begin{array}{r}14 / 26 \\
6 / 26\end{array}$ & 0.015 & \begin{tabular}{l|}
0.903 \\
1.000
\end{tabular} & & & & & \\
\hline \begin{tabular}{|l} 
DKC1 \\
HIC1 \\
\end{tabular} & $\frac{6 / 26}{3 / 26}$ & $\begin{array}{l}6 / 26 \\
3 / 26\end{array}$ & $\frac{0}{0}$ & $\begin{array}{l}1.000 \\
1.000\end{array}$ & & & & & \\
\hline
\end{tabular}

Fig. 3 The phase specific alteration in methylation of the promoter $\mathrm{CpG}$ island of the genes in liver cancer. (A) a schematic presentation of the concepts of the phase-specific methylation during carcinogenesis of live cancer. (B) the early phase genes display similar frequency of changes in both tissues, while the late phase genes change at a significantly higher rate in cancer than the neighbouring non-cancerous tissues. Both $\chi^{2}$ and $P$-values for each gene have been calculated and shown in the tables. The genes in italic and bold are decreased in methylation in cancer. $\mathrm{C}$, cancer tissues; $\mathrm{N}$, the neighbouring non-cancerous tissues, and $\mathrm{M}$, the normal liver tissues.

of testing tumorous state with the DNA from patients' body fluids (blood, saliva, ascites and etc.) and of discharges (stool, sputum and cell disposal in urine). The genes: RASSF1A, GSTP1 and SALL3 or OCT6 are the components of the most informative three target set for HCC. The detection rate for each single target was $100 \%$ and $84.6 \%$ for all the three targets in HCC cases (Tab. 2).

The altered methylation pattern in HCC has been compared with two other common solid cancers in China: the non-small cell lung cancer (NSCLC) and malignant glioma (Fig. 4). A couple of targets showed similar frequency changes in all three types of cancer. The $p 73$ gene was hypermethylated in $67.85 \%$ of HCC, $47.17 \%$ of malignant glioma and $68.57 \%$ of NSCLC. There were the targets exhibiting distinct tumor specific methylation patterns. For instance, the $p 16^{I N K 4 a}$ gene was significantly methylated in both HCC (53.85\%) and NSCLC (42.8\%), but only marginally methylated in malignant glioma $(1.89 \%)$. The $C D H 13$ gene was hypermethylated in $21.43 \%$ of liver cancer, $5.66 \%$ of malignant glioma and $71.42 \%$ of NSCLC patients. In the case of the $C D H 1$ gene, it is hypermethylated at a significantly higher rate in NSCLC $(22.86 \%)$ and malignant glioma (32.08\%) than HCC (0\%). It is clear that alteration in DNA methylation is specific to tumor type, suggesting its potential for differential diagnosis of tumor when the circulating DNA is used for testing. On the contrary, mutations of the tumor associated genes have never been shown as tumor type specific. Therefore, detection of mutations in the ras proto-oncogene and $p 53$ tumor suppressor genes in circulating DNA would not be able to determine tumor origin.

Although we have established the DNA methylation pattern concerning at least over 30 targets in four common types in China, realization of the great potential of using DNA methylation pattern for cancer diagnosis and prognosis demand enormous works of both more extensive profiling and the mechanistic delineation.

\section{THE FUTURE PERSPECTIVES}

We have witnessed a recent surge of interests in DNA methylation in the biomedical field. An international consortium (http://www.epigenome.org) was set up in 1998 to compile the methylation profile at the sequence level of the promoter region of all the human genes of seven major tissues [42, 43]. A significant progress has been made [44]. It is generally believed that the information as such would 
Tab. 2 The concordant behaviour of the methylation in liver cancer.

\begin{tabular}{cccccc}
\hline Number & $\begin{array}{c}\text { Co-occurrence } \\
\text { (Frequency)(\%) }\end{array}$ & $\begin{array}{c}\text { Occurrence of any target } \\
\text { in subset (Frequency) }\end{array}$ & The gene(s) in subset & \\
\hline 1 & $26 / 26(100)$ & $26 / 26(100)$ & RASSF1A & & \\
2 & $24 / 26(92.3)$ & $26 / 26(100)$ & RASSF1A & GSTP1 & \\
3 & $22 / 26(84.6)$ & $26 / 26(100)$ & RASSF1A & GSTP1 & SALL3 \\
3 & $22 / 26(84.6)$ & $26 / 26(100)$ & RASSF1A & GSTP1 & OCT6 \\
\hline
\end{tabular}

\begin{tabular}{|c|c|c|c|}
\hline & HCC.(26) & Glinma(53) & N.SC.I C..35 \\
\hline$A S S F 1 A$ & $100(26)$ & $69.81(37)$ & $42.85(15)$ \\
\hline OCT6 & $82.14(21)$ & $30.19(16)$ & $17.14(6)$ \\
\hline$\Delta P$ & $71.43(19)$ & $41.51(22)$ & $17.14(6)$ \\
\hline 073 & $67.86(18)$ & $47.17(25)$ & $68.57(24)$ \\
\hline$O D 1$ & $57.69(15)$ & $1.89(1)$ & $40.00(14)$ \\
\hline$p 16^{\text {INKAA }}$ & $53.85(14)$ & $1.89(1)$ & $42.86(15)$ \\
\hline WT1 & $28.57(7)$ & $30.19(16)$ & $82.85(29)$ \\
\hline $\mathrm{CDH} 13$ & $21.43(6)$ & $5.66(3)$ & $71.42(25)$ \\
\hline MGMT & $3.57(1)$ & $35.85(19)$ & $28.57(10)$ \\
\hline $\mathrm{CDH} 1$ & $0.00(0)$ & $32.08(17)$ & $22.86(8)$ \\
\hline DAPK1 & $0.00(0)$ & $0.00(0)$ & $14.29(5)$ \\
\hline$p 14^{A R F}$ & $0.00(0)$ & $0.00(0)$ & $8.57(3)$ \\
\hline$A P C$ & $0.00(0)$ & $0.00(0)$ & $17.14(6)$ \\
\hline MAGEA1 & $71.43(19)$ & $24.53(13)$ & \\
\hline
\end{tabular}

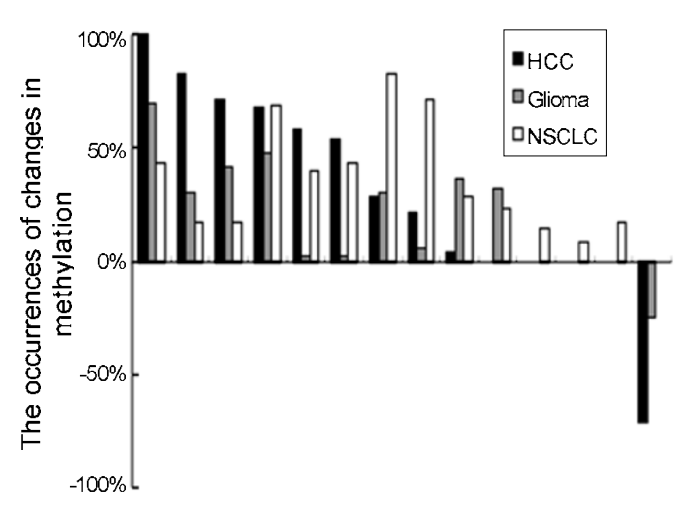

Fig. 4 The tumour type specificity of the altered DNA methylation pattern.

improve our understanding of the DNA methylation mediated regulation of gene transcription during cell differentiation and serve as a better guidance for the personalized medicine than the genetic polymorphism. An European Consortium was also formed in 2004 for a epigenome project (EPIGENETIC PLASTICITY OF THE GENOME) to cover following eight non-DNA methylation areas in epigenetics: 1. chromatin modification; 2 . nucleosome dynamics; 3 . non-coding RNA and gene silencing; 4 . Xi and imprinting; 5 . transcriptional memory; 6 . assembly and nuclear organization; 7. cell fate and disease and, 8 . epigenomic maps (http://www.epigenome-noe.net/). It could become revolutionary hallmarks when these two big projects are completed.

We are initiating an effort for the large scale methylation-profiling of genes in HCC with an ultimate goal of using it for cancer staging and classification. Certainly, this project needs the involvement of scientists from laboratory benches as well as the clinician from patient's bedside. Contributions from bioinformatics and the development of the high through-put technology are also under demand.

\section{MOLECULAR STAGING AND CLASSIFICATION OF LIVER CANCER BASED UPON THE AL- TERED PATTERN OF DNA METHYLATION: WHAT WE HAVE LEARNT AND PLANED TO DO}

There are approximately $29000 \mathrm{CpG}$ island and 25000 genes in human genome[45]. DNA methylation mediated control of transcription take place in about $40-50 \%$ of tissue-specific genes and the majority of the house-keeping genes that possess the promoter $\mathrm{CpG}$ island [46]. No less than 1358 genes have been implicated in carcinogenesis of human cancers (http://www.ncbi.nlm.nih.gov/ entrez/query.fcgi? $d b=$ gene). Application of altered pattern of DNA methylation profile to clinical use in order to monitor cancer development and treatment requires an analysis of more targets. Ultimately, the capability should be obtained to profile in clinical samples, the entire array of promoter $\mathrm{CpG}$ islands (approximately 10000) and $\mathrm{CpG}$ islands (approximately 29000) in the whole genome.

We have selected 1358 tumor related genes, through searching the NCBI database (http://www.ncbi.nlm.nih. gov/entrez/query.fcgi? $\mathrm{db}=$ gene) by using the following key 
words: apoptosis, drug resistance, oncogene, tumor suppressor, DNA repairs, genetic imprinting and mitosis, respectively. By using the $\mathrm{CpG}$ island identification software (http://www.uscnorris.com/cpgislands/cpg.cgi) [47], we have found that over $70 \%$ of genes in this list are the promoter $\mathrm{CpG}$ island containing genes. The evolutionally conserved region between the human and mouse within the promoter CpG island (http://www.ncbi.nlm.nih.gov/ genome/seq/MmBlast.html) was chosen as the target of the MSP analysis, where the primer pairs for methylationprofiling were then designed (http://micro-gen.ouhsc.edu/ cgi-bin/primer3_www.cgi). There are total 675 genes having been selected for the forthcoming methylation profiling for liver cancer samples.

It is necessary to analyze gene expression for those showing HCC specific altered DNA methylation pattern in the cancer tissue. Cellular heterogeneity in cancer tissues limits the use of biochemical methods taking RNA or protein as the targets. It is possible to use cell culture system involved with the treatment by a general DNA methyltransferase inhibitor, 5-aza-deoxylcytidine, but unpractical to analyze more than a dozen genes because of the limited capability. The immunochemical approach on the tissue array, hence, is the method of choice to correlate the methylation with the expression state of the target genes. Quality clinical information is extremely important, too. In addition to make a large collection of both HCC and the paired neighbouring non-cancerous tissues, samples representing the precancerous stage of $\mathrm{HCC}$, such as cirrhotic livers are also collected. The detailed clinical profile, including the information on the post-surgery chemotherapeutic regimes and survival should be also provided by the clinical team.

The MSP method has many advantages, but is capability is rather small due to its labouring manual procedure. It is impossible to use MSP method to obtain decent profiles for more than 500 genes in a patient cohort of more than 300 patients. For the ultimate goal to obtain a complete methylation profile on the promoter $\mathrm{CpG}$ island (approximately over 10000) as well as the $\mathrm{CpG}$ island from the whole genome (approximately 29000), an alternative method should be attempted. Up till now, the most promising method is based on affinity chromatography to extract methylated $\mathrm{CpG}$ rich DNA fraction by using the methylation binding domain of the MeCP2 protein [48, 49]. The DNA fraction enriched in methylated $\mathrm{CpG}$ from the normal and malignant cells will be individually labelled with different fluorescence. To avoid the uncertainty caused by the cellular heterogeneity in cancer samples, the initial array analyses will be executed with DNA from the normal liver tissues and from established liver cancer cell lines. The informative targets will be verified for MSP analysis in clinical samples.

The questions raised are whether we could and when could we make a difference in the survival and the life quality of cancer patients. It will certainly be a long journey.

\section{ACKNOWLEDGEMENTS}

The research performed in this lab is supported by Shanghai Science Foundation (NO. 04DZ14006), National Natural Science Foundation (NO. 30450001), Major State Basic Research Development program of China (NO. 2004CB518804) and the National High Technology Research and Development Program of China (NO. 2002AA2Z3352). Special thanks are given to Hong $\mathrm{Yu}$ ZHANG, Jian YU, and Ying Hua HE for their contribution of the data (published and unpublished) and Jian Ren GU as well as Dan Dan NIU for comments on the manuscript. This review is dedicated to the $90^{\text {th }}$ anniversary of Prof. Zhen YAO.

\section{REFERENCES}

1 Fazzari MJ, Greally JM. Epigenomics: beyond $\mathrm{CpG}$ islands. Nat Rev Genet 2004; 5:446-55.

2 Feinberg AP, Tycko B. The history of cancer epigenetics. Nat Rev Cancer 2004; 4:143-53.

3 Li E, Bestor TH, Jaenisch R. Targeted mutation of the DNA methyltransferase gene results in embryonic lethality. Cell 1992; 69:915-26.

4 Okano M, Bell DW, Haber DA, Li E. DNA methyltransferases Dnmt3a and Dnmt3b are essential for de novo methylation and mammalian development. Cell 1999; 99:247-57.

5 Esteller M. Epigenetic lesions causing genetic lesions in human cancer: promoter hypermethylation of DNA repair genes. Eur J Cancer 2000; 36:2294-300.

6 Esteller M, Toyota M, Sanchez-Cespedes M, et al. Inactivation of the DNA repair gene O6-methylguanine-DNA methyltransferase by promoter hypermethylation is associated with $\mathrm{G}$ to A mutations in K-ras in colorectal tumorigenesis. Cancer Res 2000; 60:2368-71.

7 Esteller M, Risques RA, Toyota M, et al. Promoter hypermethylation of the DNA repair gene $\mathrm{O}(6)$-methylguanineDNA methyltransferase is associated with the presence of $\mathrm{G}: \mathrm{C}$ to A:T transition mutations in p53 in human colorectal tumorigenesis. Cancer Res 2001; 61:4689-92.

8 Chen RZ, Pettersson U, Beard C, et al. DNA hypomethylation leads to elevated mutation rates. Nature 1998; 395:89-93.

9 Eden A, Gaudet F, Waghmare A, Jaenisch R. Chromosomal instability and tumors promoted by DNA hypomethylation. Science 2003; 300:455.

10 Gaudet F, Hodgson JG, Eden A, et al. Induction of tumors in mice by genomic hypomethylation. Science 2003; 300:489-92.

11 Esteller M, Fraga MF, Guo M, et al. DNA methylation patterns in hereditary human cancers mimic sporadic tumorigenesis. Hum Mol Genet 2001; 10:3001-7.

12 Oommen AM, Griffin JB, Sarath G, Zempleni J. Roles for nutrients in epigenetic events. J Nutr Biochem 2005; 16:74-7. 
13 Jaenisch R, Bird A. Epigenetic regulation of gene expression: how the genome integrates intrinsic and environmental signals. Nat Genet 2003; 33 Suppl:245-54.

14 Li E. Chromatin modification and epigenetic reprogramming in mammalian development. Nat Rev Genet 2002; 3:662-73.

15 Issa JP. CpG-island methylation in aging and cancer. Curr Top Microbiol Immunol 2000; 249:101-18.

16 Hochedlinger K, Jaenisch R. Nuclear transplantation: lessons from frogs and mice. Curr Opin Cell Biol 2002; 14:741-8.

17 Dunn BK. Hypomethylation: one side of a larger picture. Ann N Y Acad Sci 2003; 983:28-42.

18 Esteller M. Dormant hypermethylated tumor suppressor genes: questions and answers. J Pathol 2005; 205:172-80.

19 Leaf C. Why we're losing the war on cancer (and how to win it). Fortune 2004; 149:76-82, 84-6, 88 passim.

20 Gospodarowicz MK, Miller D, Groome PA, et al. The process for continuous improvement of the TNM classification. Cancer 2004; 100:1-5.

21 Lane DP. p53 and human cancers. Br Med Bull 1994; 50:58299.

22 Neibergs HL, Hein DW, Spratt JS. Genetic profiling of colon cancer. J Surg Oncol 2002; 80:204-13.

23 Kondo Y, Issa JP. Epigenetic changes in colorectal cancer. Cancer Metastasis Rev 2004; 23:29-39.

24 Bosch F, Global epidemiology of hepatocellular carcinoma. In: Okuda K, Tabor E. Eds. Liver Cancer, Churchill Livingstone: New York 1997:13-28.

$25 \mathrm{Yu}$ J, Zhang H, Gu J, et al. Methylation profiling of thirty four promoter-CpG islands and concordant methylation behaviors of sixteen genes that may contribute to carcinogenesis of malignant glioma. BMC Cancer 2004; 4:65.

$26 \mathrm{Yu}$ J, Zhang HY, Ma ZZ, et al. Methylation profiling of twenty four genes and the concordant methylation behaviours of nineteen genes that may contribute to hepatocellular carcinogenesis. Cell Res 2003; 13:319-33.

$27 \mathrm{Yu}$ J, Ni M, Xu J, et al. Methylation profiling of twenty promoter-CpG islands of genes which may contribute to hepatocellular carcinogenesis. BMC Cancer 2002; 2:29.

28 Yang Z, Shang Z, Yu J, et al. The methylation profiles of the promoter $\mathrm{CpG}$ island of nine tumor associated genes correlate with their expression in three lung cancer cell lines. Tumor 2004; 11:216-22 (In Chinese).

$29 \mathrm{Xu} \mathrm{X}, \mathrm{Yu}$ J, Zhang H, et al. Methylation profile of the promoter $\mathrm{CpG}$ islands of thirty one genes that may contribute to carcinogenesis of the colorectal cancer. World J Gastroenterol 2004; 10: 3441-54.

$30 \mathrm{Li}$ J, Fei Q, Yu J, et al. Correlation between methylation profile of promoter $\mathrm{CpG}$ islands of seven metastasis-associated genes and their expression states in six cell lines of liver origin. Chinese Journal of Cancer 2004; 23:985-91 (In Chinese).

31 Ding S, Gong B, Yu J, et al. Methylation profile of the promoter $\mathrm{CpG}$ islands of fourteen "drug-resistance" genes in hepatocellular carcinoma. World J Gastroenterol 2004; 10:3443-40.

32 Zhang K, Siino JS, Jones PR, et al. A mass spectrometric "Western blot" to evaluate the correlations between histone methylation and histone acetylation. Proteomics 2004; 4:3765-75.

33 Zhao Y, Yang J, Zhu JD. The interaction of Sp1 transcription factor with two Erg-1 sies at -71/-48 upstream contribute significantly to the promoter activity of the $H E 4$ gene in tumor cells. Tumor 2004; 24:517-25 (In Chinese).

34 Cai L, Zhu JD. The tumor-selective over-expression of the human Hsp70 gene is attributed to the aberrant controls at both initiation and elongation levels of transcription. Cell Res 2003; 13:93-109.

35 Guo JY, Xu J, Mao Q, et al. The promoter analysis of the human $C 17$ or $f 25$ gene, a novel chromosome 17 p13.3 gene. Cell Res 2002; 12:339-52.

$36 \mathrm{Xu} \mathrm{J}, \mathrm{Zhu}$ J, Ni M, et al. The ATF/CREB site is the key element for transcription of the human RNA methyltransferase like 1 (RNMTL1) gene, a newly discovered $17 \mathrm{p} 13.3$ gene. Cell Res 2002; 12:177-97.

37 Zhang J, Yu J, Gu J, et al. A novel protein-DNA interaction involved with the $\mathrm{CpG}$ dinucleotide at -30 upstream is linked to the DNA methylation mediated transcription silencing of the MAGE-A1 gene. Cell Res 2004; 14:283-94.

38 Jones PA. An epigenetic approach for finding tumor suppressors. Cell Cycle 2003; 2:25-6.

39 Markl ID, Cheng J, Liang G, et al. Global and gene-specific epigenetic patterns in human bladder cancer genomes are relatively stable in vivo and in vitro over time. Cancer Res 2001; 61:587584.

40 Herman JG, Graff JR, Myohanen S, et al. Methylation-specific PCR: a novel PCR assay for methylation status of $\mathrm{CpG}$ islands. Proc Natl Acad Sci U S A 1996; 93:9821-6.

41 Agrawal R, Imielinski T, Swami A. Mining association rules between sets of items in large databases. ACM SIGMOD Conference. ACM SIGMOD Conference 1993:207-16.

42 Eckhardt F, Beck S, Gut IG, Berlin K. Future potential of the Human Epigenome Project. Expert Rev Mol Diagn 2004; 4:60918.

43 Novik KL, Nimmrich I, Genc B, et al. Epigenomics: genomewide study of methylation phenomena. Curr Issues Mol Biol 2002; 4:111-28.

44 Rakyan VK, Hildmann T, Novik KL, et al. DNA methylation profiling of the human major histocompatibility complex: a pilot study for the human epigenome project. PLoS Biol 2004; 2:e405.

45 Cross SH, Bird AP. CpG islands and genes. Curr Opin Genet Dev 1995; 5:309-14.

46 Ioshikhes IP, Zhang MQ. Large-scale human promoter mapping using CpG islands. Nat Genet 2000; 26:61-3.

47 Takai D, Jones PA. The CpG island searcher: a new WWW resource. In Silico Biol 2003; 3:235-40.

48 Cross SH, Charlton JA, Nan X, Bird AP. Purification of CpG islands using a methylated DNA binding column. Nat Genet 1994; 6:236-44.

49 Meehan RR, Lewis JD, Bird AP. Characterization of MeCP2, a vertebrate DNA binding protein with affinity for methylated DNA. Nucleic Acids Res 1992; 20:5085-92. 